\title{
Cell-to-Cell Movement of Beet Necrotic Yellow Vein Virus: I. Heterologous Complementation Experiments Provide Evidence for Specific Interactions Among the Triple Gene Block Proteins
}

\author{
Emmanuelle Lauber, ${ }^{1}$ Claudine Bleykasten-Grosshans, ${ }^{2}$ M. Erhardt, ${ }^{1}$ S. Bouzoubaa, ${ }^{1}$ G. Jonard, ${ }^{1}$ \\ K. E. Richards, ${ }^{1}$ and H. Guilley ${ }^{1}$ \\ ${ }^{1}$ Institut de Biologie Moléculaire des Plantes du CNRS et de l'Université Louis Pasteur, 12 rue du Général \\ Zimmer, 67084 Strasbourg Cedex, France; and '2Laboratoire de Microbiologie et Génètique, Strasbourg, \\ France \\ Accepted 6 March 1998.
}

Cell-to-cell movement of beet necrotic yellow vein virus (BNYVV) requires three proteins encoded by a triple gene block (TGB) on viral RNA 2. A BNYVV RNA 3-derived replicon was used to express movement proteins of other viruses and the ability of these proteins to functionally substitute for the BNYVV TGB proteins was tested by coinoculation of TGB-defective BNYVV with the various replicons to Chenopodium quinoa. Trans-heterocomplementation was successful with the movement protein (P30) of tobacco mosaic virus but not with the tubule-forming movement proteins of alfalfa mosaic virus and grapevine fanleaf virus. Trans-complementation of BNYVV movement was also observed when all three TGB proteins of the distantly related peanut clump virus were supplied together but not when they were substituted for their BNYVV counterparts one by one. When P30 was used to drive BNYVV movement in trans, accumulation of the first TGB protein of BNYVV was adversely affected by null mutations in the second and third TGB proteins. Taken together, these results suggest that highly specific interactions among cognate TGB proteins are important for their function and/or stability in planta.

Additional keywords: benyvirus, furovirus, plant virus.

To multiply productively in a host, a plant virus must move from the initial site of infection into neighboring cells and, eventually, into the vascular compartment for long-distance transport. Two basic mechanisms for the first step, viral cell-tocell movement, have been described. Many viruses are thought to move from cell to cell as a complex between viral RNA and a virus-coded movement protein (MP), of which P30 of tobacco mosaic virus (TMV) is the best-studied example (Deom et al. 1992). P30 has multiple functions: it binds to and "streamlines" the viral RNA destined for intercellular movement, and in-

Corresponding author: H. Guilley; Institut de Biologie Moléculaire des Plantes; 12 rue du Général Zimmer; 67084 Strasbourg Cedex, France; Telephone: $3338841 \quad 72$ 51; Fax: $3338861 \quad 44$ 42; E-mail: hubert.guilley@ibmp-uLp.u-strasbg.fr creases the effective pore size of plasmodesmata joining infected and adjacent cells so that the viral RNA-MP complex can pass through them (see Ghoshroy et al. 1997, for a recent review); P30 also interacts with the plant cytoskeleton (Heinlein et al. 1995; McLean et al. 1995), which may be important in organizing intracellular transport of the viral RNA-P30 complex from sites in the cytoplasm to the plasmodesmata. Other viruses (e.g., comoviruses and nepoviruses) move from cell to cell in the form of virus particles that traverse the plasmodesmata through tubules composed at least in part of MP (Van Lent et al. 1990; Ritzenthaler et al. 1995; Kasteel et al. 1997b). Recent observations suggest that MP tubules are also involved in intercellular movement of members of the family Bromoviridae (Kasteel et al. 1997a; Zheng et al. 1997).

Beet necrotic yellow vein virus (BNYVV, former furovirus, now type member of the benyvirus group; Pringle 1997) is a fungus-transmitted virus with an RNA genome consisting of five components (reviewed by Richards and Tamada 1992). The two largest RNAs carry all the information necessary for local lesion formation on mechanically inoculated leaves while the three smaller RNAs intervene in propagation of the virus in the field. BNYVV can move intercellularly without viral coat protein $(\mathrm{CP})$ and RNA 2 encodes three proteins, $\mathrm{P} 42$, P13, and P15, that are each essential for this process (Gilmer et al. 1992a). The three MPs are encoded by overlapping genes on BNYVV RNA 2 known as the triple gene block (TGB; see Figure 1A). TGBs are present in the RNA genomes of potexviruses, carlaviruses, hordeiviruses, and some other fungus-transmitted viruses, including peanut clump pecluvirus (PCV; Herzog et al. 1994).

The corresponding TGB proteins in different viruses are similar in structure and, presumably, function. Thus, the $5^{\prime}$ proximal TGB protein (referred to generically as TGBp1) invariably contains sequence motifs signaling an ATP/GTPdependent RNA helicase (Gorbalenya and Koonin 1989). TGBp1 binds RNA in vitro (Rouleau et al. 1994; Bleykasten et al. 1996; Kalinina et al. 1996; Donald et al. 1997) and the TGBp1 of potato virus X (PVX), probably in conjunction with one or both of the other TGB proteins, provokes an increase in the plasmodesmatal size exclusion limit of Nicotiana cleve- 
landii tricome cells (Angell et al. 1996). In the case of BNYVV, TGBp1 (P42) is primarily associated with a membrane-rich subcellular fraction (Niesbach-Klösgen et al. 1990). For other viruses, TGBp1 has been detected in a cell-wallenriched subcellular fraction (Donald et al. 1993) and, by immune electron microscopy, in association with cytoplasmic inclusion bodies (Davies et al. 1993; Rouleau et al. 1994). Whether the TGBp1 in any of these locations is functional remains an open question.

The second TGB protein (TGBp2) contains a highly conserved central motif flanked by potentially membrane-spanning, hydrophobic domains and is associated with a membrane-rich subcellular fraction from infected plants (Niesbach-Klösgen et al. 1990; Donald et al. 1993). The third protein, TGBp3, is more variable in size and sequence in the different viruses but is always rather hydrophobic. Recently, the PVX TGBp3 has been localized in the cell wall of virus-infected and TGBp3expressing transgenic plants (Hefferon et al. 1997), but the TGBp3s of other viruses have so far escaped detection.

The mechanism by which the TGB proteins intervene in cell-to-cell movement is not understood, nor is it known how closely the process resembles the TMV model. The fact, however, that the movement-related functions are shared out among the three TGB proteins suggests that they are expressed and act in a highly regulated fashion. Evidence for this has come from trans-complementation experiments in which overproduction of BNYVV TGBp3 (P15) was shown to inhibit cell-to-cell movement of viral RNA (BleykastenGrosshans et al. 1997). In the normal situation, TGBp2 and TGBp3 are both translated from the same subgenomic RNA (Morozov et al. 1991; Zhou and Jackson 1996; BleykastenGrosshans et al. 1997), which probably provides a mechanism for coordinating their relative rates of synthesis throughout the viral infection cycle.

There are numerous examples illustrating that the MP of one virus can complement cell-to-cell movement of a second virus, even when the two viruses belong to different taxonomic groups (reviewed by Atabekov and Taliansky 1990). Heterologous complementation of this sort has been observed for TGB-containing viruses. For example, it has recently been shown that a chimera in which the TGB on RNA $\beta$ of barley stripe mosaic virus (BSMV) was replaced by the P30 gene can move from cell to cell in hosts common to BSMV and TMV (Solovyev et al. 1996). The MPs of two tobamoviruses and of red clover necrotic mosaic dianthovirus also trans-complemented TGBp1-defective PVX when expression vectors containing the virus and the MPs were co-delivered to hosts by microprojectile bombardment (Morozov et al. 1997).

In this paper, we have used a BNYVV RNA 3-based replicon to test for heterologous complementation of BNYVV movement with different movement proteins. Successful trans-complementation was obtained with TMV P30 and the PCV TGB proteins but not with tubule-forming MPs. The PCV TGB proteins supported BNYVV movement when supplied together, but not when substituted for the corresponding BNYVV TGB proteins one by one. Using the P30-based trans-complementation system, we have also investigated the fate of the BNYVV TGB1 and TGB2 proteins in planta when one of the other TGB proteins on RNA 2 has been eliminated by mutation. Our findings suggest that highly specific interactions occur among the TGB proteins.

\section{RESULTS AND DISCUSSION}

\section{Expression of heterologous MPs from a BNYVV RNA 3 replicon.}

We have previously shown that a viral RNA "replicon" (rep0; Fig. 1B) created by deletion of the central replicationdispensable portion of BNYVV RNA 3 can, when coinoculated to Chenopodium quinoa leaves with BNYVV RNAs 1 and 2, replicate and express inserted genes (Jupin et al. 1990; Hehn et al. 1995; Bleykasten-Grosshans et al. 1997). In this paper, we have inserted the MP genes of different viruses into rep0 to test their ability to trans-complement cell-to-cell movement of TGB-defective BNYVV. The movement proteins tested were (i) P30 of TMV, (ii) the tubule-forming MPs of grapevine fanleaf nepovirus (GFLV; P38) and alfalfa mosaic ilarvirus (AlMV; P32), and (iii) the TGB proteins of PCV. The three PCV TGB genes, encoding P51, P14 and P17, were inserted into the replicon either as a unit (rep-PCV-TGB; see Figure 1B for all replicon structures), separately (repPCVP51, rep*PCV-P51, repPCV-P14, repPCV-P17) or in a dicistronic configuration (repPCV-P14-P17).

Northern (RNA) hybridization revealed that the replicons containing the different MPs all multiplied efficiently when inoculated with BNYVV RNAs 1 and 2 to $C$. quinoa protoplasts and did not interfere with accumulation of the "helper" BNYVV RNA 1 and 2 (Fig. 2, lanes 4 to 11). Proteins were extracted from the infected protoplasts and tested for expression of the heterologous MPs with antisera specific for PCV P51 (Fig. 3A), TMV P30 (Fig. 3B), AlMV P32 (Fig. 3C), and GFLV P38 (Fig. 3D). In each case a band corresponding in apparent $M_{\mathrm{r}}$ to the expected heterologous MP was detected. No antisera specific for PCV TGBp2 (P14) and TGBp3 (P17) are available. However, wheat germ extracts programmed with repPCV-P14, repPCV-P17, and repPCV-P14-P17 synthesized proteins of the expected $M_{\mathrm{r}}$ (data not shown; repPCVP14-P17 directed synthesis of both P14 and P17), suggesting that the replicons should be translationally active in vivo as well. Furthermore, we have shown previously (BleykastenGrosshans et al. 1997) that repPCV-P17 inhibits viral cell-tocell movement when inoculated with BNYVV RNAs 1 and 2 to $C$. quinoa leaves, which argues strongly that the replicon directs P17 synthesis in planta.

\section{The TGB proteins of PCV complement BNYVV movement when expressed together but not when expressed separately.}

It is known that the BNYVV TGB proteins, when expressed from an RNA 3-based replicon, can function in trans to permit cell-to-cell movement of BNYVV in which the corresponding TGB gene on RNA 2 has been disabled by mutation (Bleykasten-Grosshans et al. 1997). In view of the structural similarities between the TGB proteins of different viruses, experiments were carried out to determine if the TGB proteins of PCV can also substitute for their BNYVV counterparts when provided in trans. Wild-type BNYVV RNA 1 transcript (t15) and a BNYVV RNA 2 transcript mutated by frameshift in either the first (tB2-14-H), second (tB2-14-I), or third (tB214-J) TGB gene (see Figure 1A) were coinoculated to $C$. quinoa leaves with the replicon expressing the corresponding TGB protein from PCV (repPCV-P51, -P14, and -P17, respectively). C. quinoa is a local lesion host for both BNYVV 

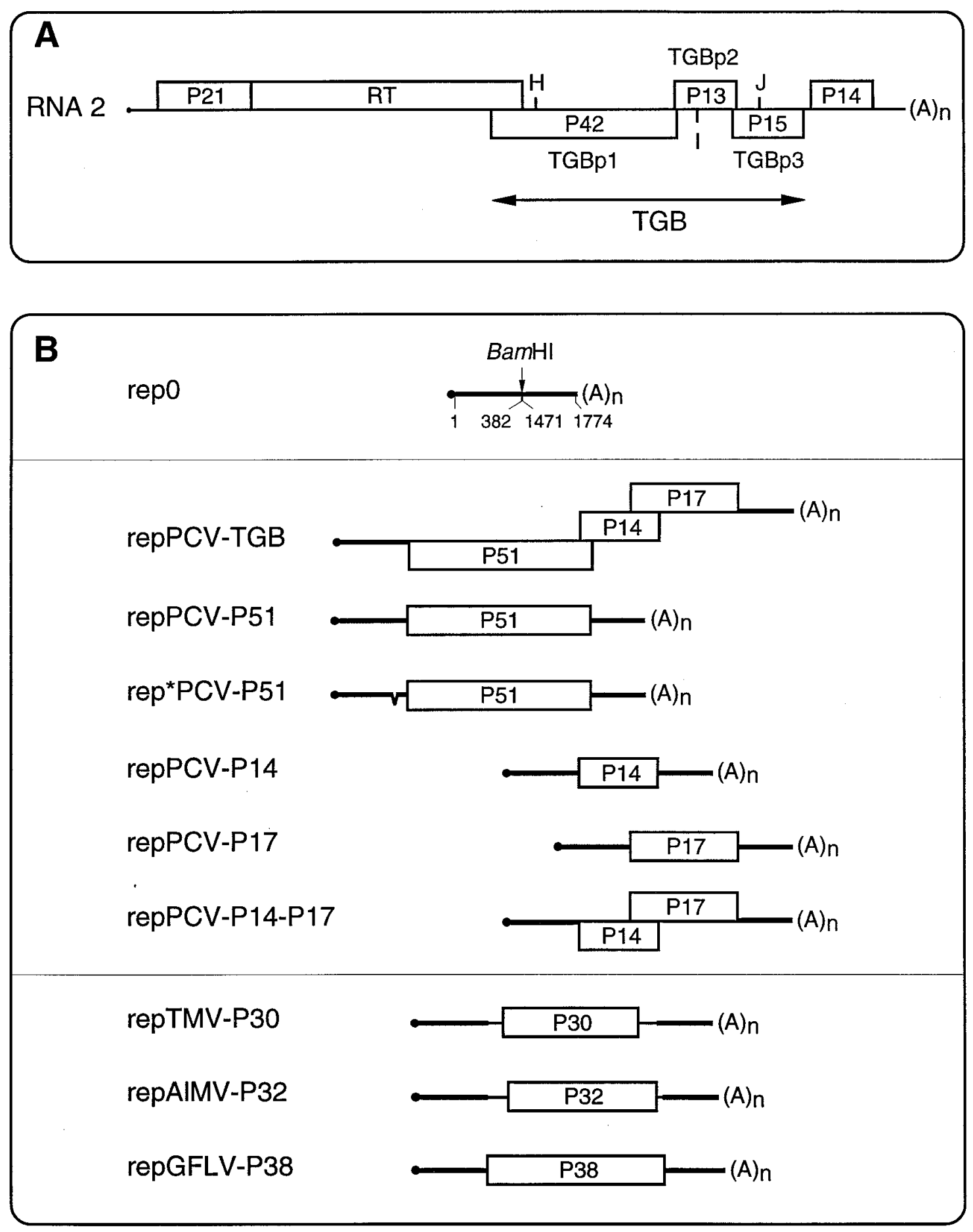

Fig. 1. Structure of beet necrotic yellow vein virus (BNYVV) RNA 2 and of replicons designed to express heterologous viral movement proteins (MPs). In all the maps, viral genes are represented by rectangles and (A)n signifies a 3'-poly(A) tail. A, Genome map of BNYVV RNA 2. Open reading framelabeled readthrough (RT) is expressed by translational RT of the termination codon of the major capsid protein P21. Positions of frameshift mutations designed to truncate each triple gene block (TGB) protein are indicated by a single letter code: H (fill-in of the SpeI site at nucleotide 2279), I (insertion of 4 nucleotides at nucleotide 3450, creating an XhoI site), and J (fill-in of the EcoRI site at nucleotide 3948). B, Structures of BNYVV RNA 3-derived replicons containing the MP genes of different viruses. Upper panel, structure of the empty replicon rep0. Numbering refers to coordinates of RNA 3 residues still present in the replicon; position of the BamHI site used for insertion of foreign genes into pRep0 is indicated. Middle panel, replicons containing one or more of the TGB genes of peanut clump virus (PCV). rep*PCV-P51 is a derivative of repPCV-P51 in which nucleotides 294 to 330 of the 5 ' nontranslated region of RNA 3 were deleted (symbolized by broken line). Bottom panel, replicons expressing tobacco mosaic virus (TMV) P30, alfalfa mosaic virus (AlMV) P32, and grapevine fanleaf virus (GFLV) P38. 
and PCV. No symptoms were observed on the inoculated leaves or on upper noninoculated leaves even at late times (20 days) post-inoculation (pi) and no progeny viral RNA was detectable by Northern hybridization (Fig. 4, lanes 2, 3, and 5). Trans-complementation of tB2-14-I also failed when the PCV TGBp2 gene was provided as the first gene of the dicistronic construct repPCV-P14-P17 (Fig. 4, lane 4).

For TGBp3, we have previously shown that independent expression of the BNYVV TGB3 protein (P15) from a replicon failed to complement TGB3-defective RNA 2 and, furthermore, blocked cell-to-cell movement of wild-type

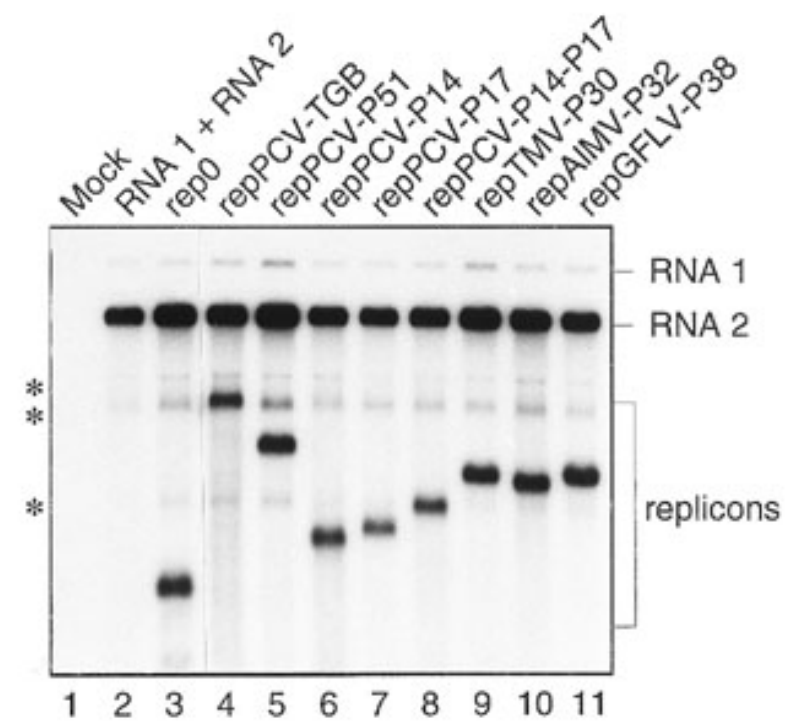

Fig. 2. Amplification of replicons encoding different movement proteins (MPs) in Chenopodium quinoa protoplasts. Detection by Northern (RNA) hybridization of viral RNAs inoculated with beet necrotic yellow vein virus (BNYVV) RNAs 1 and 2 alone (lane 2) or supplemented with replicon indicated at top of each lane. RNA from mock-inoculated protoplasts is shown in lane 1. Protoplasts were harvested $48 \mathrm{~h}$ post inoculation; viral RNAs and replicons were detected with a mixture of ${ }^{32} \mathrm{P}$ labeled antisense RNA probes specific for BNYVV RNAs 1, 2, and 3 . Other faint bands present in all lanes except lane 1 result from ribosomal RNA shadowing (Palukaitis et al. 1983).
BNYVV (Bleykasten-Grosshans et al. 1997). The inhibitory effect of replicon-expressed P15 on BNYVV movement was lifted if the TGB3 gene was placed in the replicon downstream of the BNYVV TGB2 gene (P13), probably because the proper relative rates of expression of $\mathrm{P} 15$ and $\mathrm{P} 13$ are restored in this configuration. It could thus be argued that the failure of repPCV-P17 to substitute for the defective BNYVV TGB3 protein might similarly be due to over-expression of $\mathrm{P} 17$ relative to $\mathrm{P} 13$. The dicistronic construct repPCV-P14P17 also failed to trans-complement tB2-14-J (Fig. 4, lane 6), however, making such an explanation unlikely.

Other experiments were carried out to determine if transcomplementation of BNYVV movement can occur when all three PCV TGB proteins are provided together. No lesions appeared and no progeny viral RNA was produced when the replicon containing the entire TGB cassette (repPCV-TGB) was coinoculated to $C$. quinoa leaves with $\mathrm{t} 15$ and a BNYVV RNA 2 triple mutant (tB2-14-HIJ), in which all three TGB proteins had been disabled by frameshift (data not shown). However, this failure could be due to nonexpression of TGBp2 and TGBp3 from the replicon, as these two proteins are likely expressed from a subgenomic RNA in a normal PCV infection and no mechanism for production of such a subgenomic RNA would exist in the heterocomplementation experiment. Accordingly, a third trans-complementation experiment was performed with the PCV TGB genes placed on two separate replicons, one (repPCV-P14-P17) encoding TGBp2 and TGBp3 and one (rep*PCV-P51) encoding TGBp1. rep*PCV-P51 is a derivative of repPCV-P51 in which nucleotides 294 to 330 of the $5^{\prime}$ nontranslated region of RNA 3 have been deleted (Fig. 1B). It was used instead of repPCV-P51 because control experiments indicated that coinoculated replicons with identical $5^{\prime}$ nontranslated regions sometimes "competed" with one another during amplification in planta so that one or the other was not represented in the progeny RNA (data not shown). Preliminary experiments showed that rep*PCV-P51 replicated and expressed P51 as well as repPCV-P51 when coinoculated to $C$. quinoa with BNYVV RNA 1 and 2 (data not shown).

C. quinoa leaves inoculated with the quaternary transcript mixture (t15, tB2-14-HIJ, rep*PCV-P51, and repPCV-P14-
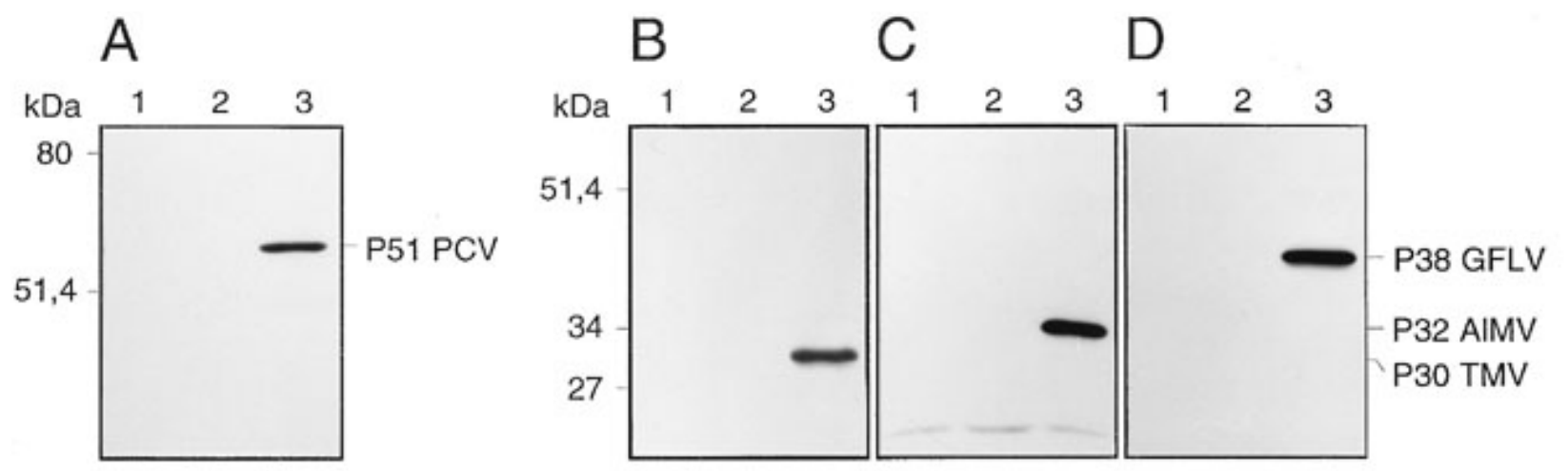

Fig. 3. Immunodetection of heterologous viral movement proteins (MPs) in total protein extracts of Chenopodium quinoa protoplasts inoculated with beet necrotic yellow vein virus (BNYVV) RNAs 1 and 2 plus a replicon containing the gene for (A, lane 3) peanut clump virus (PCV) P51, (B, lane 3) tobacco mosaic virus (TMV) P30, (C, lane 3) alfalfa mosaic virus (AlMV) P32, or (D, lane 3)grapevine fanleaf virus (GFLV) P38. In each panel, protein extracted from mock-inoculated protoplasts was loaded in lane 1 and protein from protoplasts inoculated with BNYVV RNAs 1 and 2 was loaded in lane 2. After polyacrylamide gel electrophoresis (Laemmli 1970) on a (A) 10\% or (B-D) 12\% polyacrylamide gel and electrotransfer to Immobilon-P, the heterologous MPs were immunodetected with antisera specific for (A) P51, (B) P30, (C) P32, and (D) P38. Positions of selected molecular mass markers are indicated in $\mathrm{kDa}$ to the left. 
P17) developed chlorotic local lesions 9 to 10 days pi, a delay of 2 to 3 days compared with the time of symptom onset with wild-type BNYVV transcripts. Progeny RNA corresponding to all the components of the inoculum were detected by Northern blot (Fig. 4, lane 7) and reverse transcriptionpolymerase chain reaction (RT-PCR) analysis confirmed that the mutations disabling the BNYVV TGB genes were still present in the progeny RNA 2 (data not shown). Thus, the PCV TGB proteins can trans-complement BNYVV movement when supplied together in an appropriate configuration but are not active when substituted for their BNYVV counterparts on a one-for-one basis.

\section{P30 trans-complements BNYVV cell-to-cell movement.}

In view of the ability of P30 from TMV to substitute for the TGB movement functions of BSMV (Solovyev et al. 1996) and PVX (Morozov et al. 1997), we tested whether an RNA 3based replicon containing P30 (repTMV-P30) can transcomplement a TGB-defective BNYVV RNA 2 mutant. repTMV-P30 was inoculated to $C$. quinoa leaves with $\mathrm{t} 15$ and the BNYVV RNA 2 triple mutant tB2-14-HIJ. Chlorotic local lesions appeared on the inoculated leaves and progeny RNAs

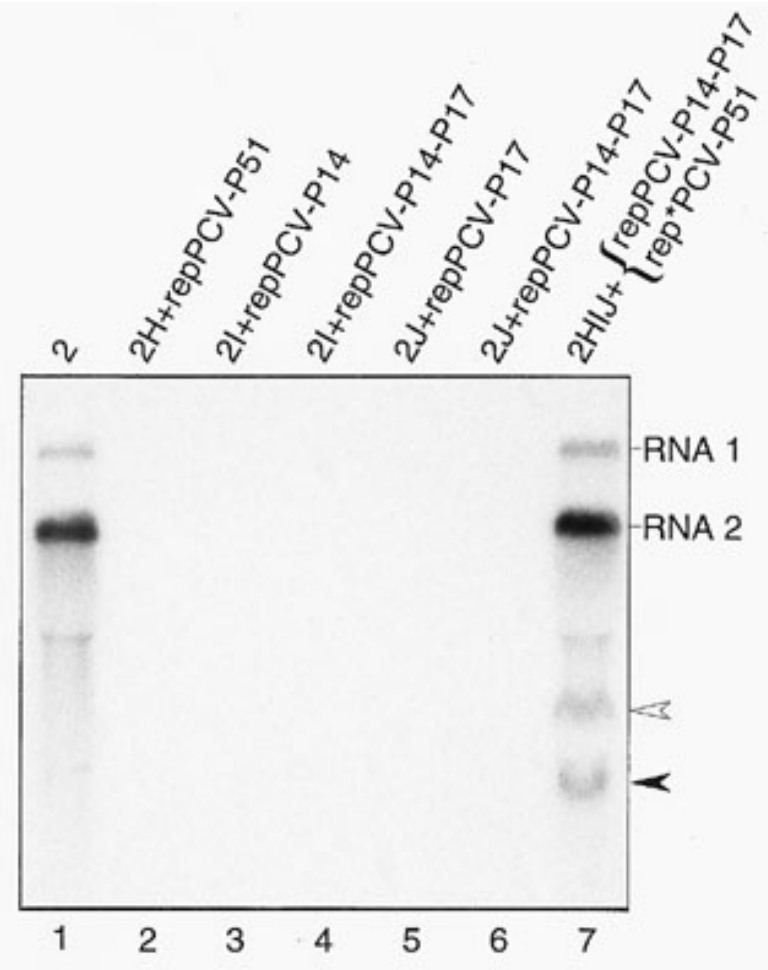

Fig. 4. Trans-complementation of beet necrotic yellow vein virus (BNYVV) RNA 2 transcripts containing frameshift mutations in different triple gene block (TGB) genes by replicons containing one or more of the TGB genes of peanut clump virus (PCV). Chenopodium quinoa leaves were inoculated with wild-type RNA 1 transcript (t15) plus either wild-type RNA 2 transcript tB2-14 (lane 1) or the mutant RNA 2 transcript identified above each lane. Designations of the various RNA 2 transcripts are abbreviated: $2 \mathrm{I}=\mathrm{tB} 2-14-\mathrm{I}$ etc. In lanes 2 to 6 , inoculum was supplemented with the replicon indicated above each lane. In lane 7 , inoculum was supplemented with two replicons: rep*PCV-P51 and repPCV-P14-P17. Inoculated leaves were harvested 10 days post-inoculation and tested for viral RNA contents by Northern (RNA) hybridization as described in Figure 2. Position of progeny rep*PCV-P51 is indicated by a white arrowhead; that of repPCV-P14-P17 by a black arrowhead.
1 and 2 plus repTMV-P30 were readily detected by Northern hybridization (Fig. 5, lane 6). The time of symptom onset was similar to that observed for inoculations of wild-type RNAs 1 and 2 with or without the empty replicon rep0 (data not shown), but the local lesions developed to only about half the size of those produced by a wild-type infection. Addition of repTMV-P30 to a wild-type RNA 1 and 2 inoculum produced a more aggressive infection, with local lesions appearing earlier (3 to 4 days pi) and expanding more rapidly than when the P30-expressing replicon was omitted (data not shown). Thus, the two movement systems apparently act synergistically when present together during an infection.

RepTMV-P30 successfully trans-complemented BNYVV cell-to-cell movement when only one of the three TGB members in the RNA 2 transcript had been disabled by frameshift (Fig. 5, lanes 3 to 5) or when any combination of two TGB genes was mutated (data not shown). Time of symptom onset and lesion size were similar to those observed for P30 complementation of tB2-14-HIJ. We conclude that P30 can substitute for all three TGB proteins but that trans-complemented movement may be somewhat less efficient than that observed in the natural situation. Furthermore, simultaneous expression of one or two of the three BNYVV TGB proteins along with P30 neither interfered with nor enhanced P30-mediated, cellto-cell movement (Fig. 5, and data not shown).

\section{Tubule-forming MPs do not trans-complement BNYVV movement.}

The replicons containing the genes for the tubule-forming MPs of AlMV (repAlMV-P32) and GFLV (repGFLV-P38) failed to complement BNYVV movement when inoculated to C. quinoa leaves with $\mathrm{t} 15$ and any of the BNYVV RNA 2

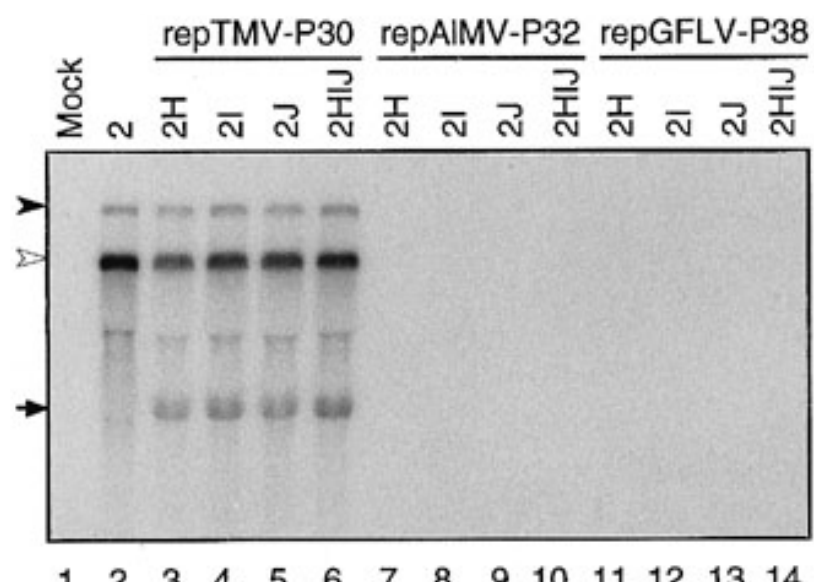

Fig. 5. Trans-complementation of beet necrotic yellow vein virus (BNYVV) RNA 2 transcripts with frameshift mutations in different triple gene block (TGB) genes by replicons expressing different movement proteins (MPs). Chenopodium quinoa leaves were inoculated with wild-type RNA 1 transcript (t15) plus either wild-type RNA 2 transcript tB2-14 (lane 2) or the mutant RNA 2 transcript identified above each lane. Designations of various RNA 2 transcripts are abbreviated: $2 \mathrm{I}=\mathrm{tB} 2-14-\mathrm{I}$ etc. Inoculum also included a replicon encoding tobacco mosaic virus (TMV) P30 (lanes 3 to 6), alfalfa mosaic virus (AlMV) P32 (lanes 7 to 10), or grapevine fanleaf (GFLV) P38 (lanes 11 to 14). RNA from inoculated leaves was tested for viral RNA contents by Northern (RNA) hybridization as described in Figure 2. Lane 1 contains RNA from a mock-inoculated plant. Positions of progeny RNA 1 and 2 are indicated by black and white arrowheads; position of progeny repTMV-P30 by a black arrow. 
TGB mutants described above (Fig. 5, lanes 7 to 14). Morozov et al. (1997) have similarly observed that the tubuleforming MP of brome mosaic virus (BMV) did not transcomplement movement of PVX when coinoculated by particle bombardment although coinfection of PVX with $\mathrm{BMV}$ has been reported to enable PVX movement on certain nonhosts (Atabekov and Taliansky 1990). We conclude that TGB-defective BNYVV is not complemented by the unique expression of a tubule-forming MP but we cannot rule out the possibility that movement might occur in the context of an infection with a helper virus expressing such a protein.

\section{Mutation of TGBp2 and TGBp3 inhibits accumulation of TGBp1.}

The P30-based heterologous complementation system provides a convenient tool for investigating the behavior of a given TGB protein in planta when one or more of its partners have been eliminated by mutagenesis. Figure 6 shows immunodetection of $\mathrm{P} 42, \mathrm{P} 13$, and the major viral CP in total proteins extracted from pooled local lesions from $C$. quinoa leaves infected with t15, repTMV-P30, and either the wildtype RNA 2 transcript tB2-14 or an RNA 2 transcript with a

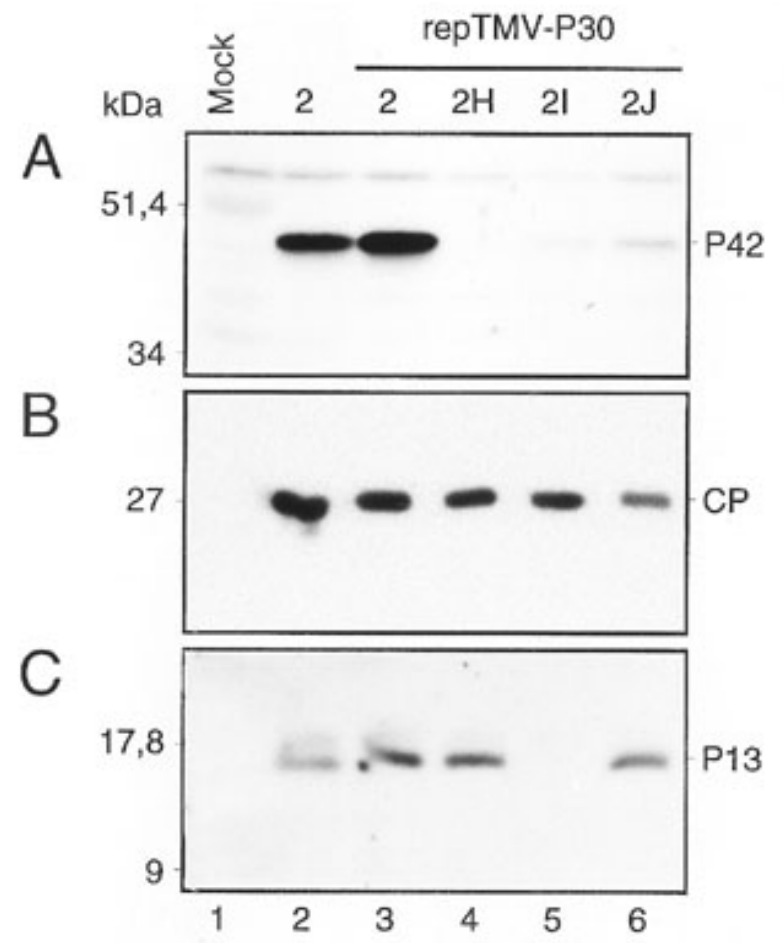

Fig. 6. Knock-out mutations in the beet necrotic yellow vein virus (BNYVV) triple gene block (TGB) proteins P13 and P15 inhibit accumulation of P42. Leaves of Chenopodium quinoa were inoculated with the RNA 1 transcript (t15) plus the wild-type RNA 2 transcript tB2-14 (lanes 2 and 3) or the RNA 2 mutant transcript tB2-14H (lane 4), tB214-I (lane 5), or tB2-14-J (lane 6). Inoculum was supplemented with repTMV-P30 in lanes 3 to 6 . Protein was extracted from inoculated leaves 8 days post-inoculation and separated by polyacrylamide gel electorphoresis (Laemmli 1970) through (A and B) a $12 \%$ polyacryamide gel and (C) a $12.5 \%$ glycerol-containing polyacrylamide gel (Schägger and von Jagow 1987). After electrotransfer to Immobilon-P, immunodetection was with an antiserum specific for (A) P42, (B) viral coat protein $(\mathrm{CP})$, or (C) P13. Protein analyzed in lane 1 was extracted from a mock-inoculated leaf. Positions of selected molecular mass markers are indicated in $\mathrm{kDa}$ to the left. frameshift mutation in one of the TGB genes, i.e., tB2-14-H, tB2-14-I, or tB2-14-J. P42 was readily detected in the proteins extracted from tissue infected with wild-type RNA 1 and 2 transcripts whether or not repTMV-P30 had been included in the inoculum (Fig. 6A, lanes 2 and 3). As expected, no P42 was detected when the TGB1 frameshift mutant tB2-14-H was substituted for the wild-type RNA 2 transcript (Fig. 6A, lane 4). Unexpectedly, however, frameshift mutagenesis of TGB2 (mutant tB2-14-I; Fig. 6A, lane 5) and TGB3 (mutant tB2-14J; Fig. 6A, lane 6) reproducibly lowered P42 accumulation levels to near the limits of immunodetection. The effect on P42 levels of the TGB3 mutation was consistently about twofold less than the effect observed with the TGB2 mutation (compare Figure 6A, lanes 5 and 6). Accumulation of the major BNYVV $\mathrm{CP}$ in the same protein samples was not greatly affected by the mutations in the different TGB genes (Fig. 6B) and Northern blot analysis of RNA extracted from the same tissues revealed that progeny viral RNA levels were also little affected (data not shown).

Immunodetection experiments on the same protein samples with a P13-specific antiserum revealed that accumulation of TGBp2 (P13), on the other hand, was not significantly inhibited by frameshift mutagenesis of TGB1 (Fig. 6C, lane 4) and TGB3 (Fig. 6C, lane 6). The effect of mutations in TGB1 and TGB2 on TGBp3 (P15) levels could not be analyzed because no antiserum of sufficient sensitivity to detect the latter protein is available.

\section{Concluding remarks.}

The mechanism by which the TGB proteins intervene in cell-to-cell movement is not known but a plausible scenario is that the hydrophobic TGBp2 and TGBp3 provide a docking site for a TGBp1-viral RNA complex at the plasmodesmata where TGBp1 (perhaps in conjunction with one or both of the other proteins) alters the plasmodesmatal size exclusion limit and potentiates transit of the viral RNA. Such a model implies that at least transient physical interactions occur among the TGB proteins and in this paper we have provided two independent lines of evidence for this. First, the inability of the PCV TGB proteins to substitute individually for their BNYVV counterparts suggests that TGB-mediated, cell-tocell movement requires specific "lock-and-key" contacts among cognate TGB proteins and that functional substitution of a heterologous TGB protein is forbidden because it lacks the proper binding site(s) to participate in such interactions.

The second line of evidence for interactions among the TGB proteins comes from the effect of the TGB2 and TGB3 null mutations on P42 stability when BNYVV movement is driven by heterologous expression of TMV P30. If, as suggested above, P13 and P15 intervene either simultaneously or successively in P42 docking at the plasmodesmata, the elimination by mutation of one or the other protein would be expected to strand P42 in the cytosol where it could be subject to degradation or activate a hypothetical feedback cycle to down-regulate its own synthesis. Accumulation of P13, on the other hand, is not influenced by the TGB1 and TGB3 null mutations, suggesting that P13 is either an inherently stable protein or is stabilized by its association with membranes. Analysis of P42 accumulation after introduction of various point mutations in P13 and P15 should provide a means of mapping the contact sites on the TGB proteins implicated in the putative docking interactions. 


\section{MATERIALS AND METHODS}

\section{Transcription vectors.}

The transcription vectors $\mathrm{pB} 15$ and $\mathrm{pB} 2-14$ and the TGB mutants pB2-14-H, -I, and -J have already been described (Quillet et al. 1989; Gilmer et al. 1992a; BleykastenGrosshans et al. 1997). The TGB double mutants pB2-14-HI and pB2-14-IJ were derived from plasmid pB2-14-I by linearization with SpeI and EcoRI, respectively, treatment with the Klenow fragment of Escherichia coli DNA polymerase in the presence of deoxyribonucleoside triphosphates to fill in recessive ends, and recircularization with bacteriophage T4 DNA ligase. The double mutant $\mathrm{pB} 2-14-\mathrm{HJ}$ was similarly prepared from EcoRI-linearized pB2-14-H and the triple mutant pB214-HIJ was obtained in the same manner from pB2-14-HI.

The TGB cistrons from PCV RNA 2 were amplified by PCR from pPC2 (Herzog et al. 1995) with flanking primers designed to amplify the entire TGB (nucleotides 2690 to 4668), the P51 gene (TGB1; nucleotides 2690 to 4030), the P14 gene (TGB2; nucleotides 3996 to 4360), the P17 gene (TGB3; nucleotides 4207 to 4668), or both the P14 and P17 genes (nucleotides 3996 to 4668). Each plus-sense PCR primer had a 5'-terminal, nonviral $N c o$ I site and each minussense primer a 5 'terminal, nonviral BamHI site. After digestion with $\mathrm{NcoI}$ and BamHI, and fill-in of recessed extremities with Klenow fragment, the PCR fragments were inserted into the filled-in BamHI site of pRep0 (Bleykasten-Grosshans et al. 1997). A clone containing each of the TGB inserts in the proper orientation was selected by restriction enzyme analysis and the entire insert was sequenced to rule out the existence of mutations introduced by PCR. The resulting plasmids are referred to as pRepPCV-TGB, pRepPCV-P51, pRepPCV-P14, pRepPCV-P17, and pRepPCV-P14-P17. Plasmid pRep*PCVP51, in which nucleotides 294 to 330 of the $5^{\prime}$ nontranslated region of RNA 3 had been deleted, was obtained by replacing the NheI-SpeI fragment from pRepPCV-P51 with the corresponding fragment of pBA4 (Gilmer et al. 1992b).

The TMV P30 gene was excised on an EcoRI-BamHI fragment from the plasmid pTM 934 (Oliver et al. 1986), recessed extremities were filled in with Klenow fragment followed by insertion into BamHI-cleaved, blunt-ended pRep0-Xho, a derivative of $\mathrm{pRep0}$ in which the HindIII site used to linearize the plasmid for transcription had been replaced by an XhoI site. The resulting plasmid is referred to as pRepTMV-P30. The AlMV P32 gene was excised as a SalI-BamHI fragment from pSel1.P3N (Schoumacher et al. 1994), rendered bluntended, and inserted into BamHI-cleaved, blunt-ended pRep0$\mathrm{Xba}$, a pRep0 derivative in which the HindIII site was replaced by an XbaI site to produce pRepAlMV-P32. An EcoRV fragment containing the GFLV P38 gene engineered to have a 5 -terminal initiation codon (AUG) and a 3 '-terminal stop codon (UGA) was a gift of Lothaire Pinck. The fragment was inserted into BamHI-cleaved, blunt-ended pRep0 to produce pRepGFLV-P38. Unless otherwise noted, all cloning and DNA manipulation employed conventional procedures (Sambrook et al. 1989).

\section{Preparation of transcripts and inoculation of plants and protoplasts.}

BNYVV RNA transcripts will be referred to by the name of the parent plasmid prefixed by the letter " $t$ " (e.g., t15, t2-14, etc.). Replicon transcripts are referred to by the name of the parent plasmid but without the letter "p". Capped transcripts were prepared by bacteriophage $\mathrm{T} 7$ polymerase run-off transcription (Quillet et al. 1989) of plasmid DNA linearized by HindIII for pB15 and most of the replicon constructs, by SalI for pB2-14 and related constructs, by XhoI for pRepTMV-P30, and by XbaI for pRepAlMV-P32. The amount of full-length transcript produced was evaluated by agarose gel electrophoresis. Transcripts were inoculated to $C$. quinoa leaves without further purification as described (Quillet et al. 1989) but for inoculation to $C$. quinoa protoplasts, the DNA template was first eliminated by treatment with DNase (Veidt et al. 1992). For protoplast infections, $0.5 \mu \mathrm{g}$ of viral RNA 1 and 2 plus 5 $\mu \mathrm{g}$ of replicon transcript was inoculated to $2 \times 10^{5}$ protoplasts by electroporation (Gilmer et al. 1992a).

\section{Detection of progeny viral RNA.}

Total RNA was isolated from infected protoplasts 24 to $48 \mathrm{~h}$ pi and from plants 8 to 10 days pi (Gilmer et al. 1992a). The total RNA was analyzed for the presence of viral RNA 1 and 2 by Northern hybridization with ${ }^{32} \mathrm{P}$-labeled antisense viral RNA probes (Lemaire et al. 1988; Bleykasten-Grosshans et al. 1997). Replicons were detected with a ${ }^{32} \mathrm{P}$-labeled RNA probe complementary to nucleotides 1 to 380 . The stability of the frameshift mutations introduced into RNA 2 was tested by RTPCR of DNase-treated total RNA extracted from inoculated leaves. cDNA was produced with Moloney murine leukemia virus reverse transcriptase (Promega-France, Charbonnières, France) (Gilmer et al. 1992a). PCR was carried out essentially as described (Brault et al. 1995) with 25 cycles of amplification in the following conditions: $94^{\circ} \mathrm{C}(30 \mathrm{~s}), 50^{\circ} \mathrm{C}(30 \mathrm{~s}), 72^{\circ} \mathrm{C}(30 \mathrm{~s}$ per $500 \mathrm{bp}$ ). The minus-strand primer for cDNA synthesis and PCR was complementary to nucleotides 4128 to 4148 . The plusstrand primers for amplification of the $\mathrm{P} 42$ gene corresponded to nucleotides 2133 to 2155 and to nucleotides 2997 to 3015 for the $\mathrm{P} 13$ and $\mathrm{P} 15$ genes. The persistence of the mutations in the progeny RNA 2 was confirmed both by restriction enzyme digestion and by sequence analysis of the PCR products.

\section{Detection of viral proteins.}

Rabbit polyclonal antisera specific for PCV P51, TMV P30, AlMV P32, and GFLV P38 were gifts. The antisera specific for BNYVV P42, P13, and the major BNYVV CP (P21) have been described (Niesbach-Klösgen et al. 1990). For immunoblots, infected leaf tissue ( $0.8 \mathrm{mg}$ per gel lane) was homogenized in $100 \mu \mathrm{l}$ of $2 \times$ gel loading buffer and proteins were separated by polyacrylamide gel electrophoresis (Laemmli 1970) in 10\% polyacrylamide for PCV P51 and $12 \%$ polyacrylamide for all the other proteins except for BNYVV P13, which was detected after separation in a $12.5 \%$ glycerol-containing polyacrylamide gel (Schägger and von Jagow 1987). After electrotransfer of proteins to Immobilon-P (Millipore, Yvelines, France), immunodetection was carried out with an enhanced chemiluminescence kit (Amersham, Les Ulis, France) according to the supplier's instructions.

\section{ACKNOWLEDGMENTS}

We thank Anne Berna and Roger Beachy for the TMV P30 gene and antiserum, Christiane Garaud and Thérese Godefroy-Colburn for the AlMV P32 gene and antiserum, Lothaire Pinck for the GFLV P38 gene and antiserum, and Christiane Fritsch for the PCV TGB genes. Daniele 
Schiedecker provided skilled technical assistance and Philippe Hammann carried out the sequence analyses.

\section{LITERATURE CITED}

Angell, S. M., Davies, C., and Baulcombe, D. C. 1996. Cell-to-cell movement of potato virus $\mathrm{X}$ is associated with a change in the sizeexclusion limit of plasmodesmata in trichome cells of Nicotiana clevelandii. Virology 316:197-201.

Atabekov, J. G., and Taliansky, M. E. 1990. Expression of a plant viruscoded transport function by different viral genomes. Adv. Virus Res. 38:201-248.

Bleykasten, C., Gilmer, D., Guilley, H., Richards, K. E., and Jonard, G. 1996. The beet necrotic yellow vein virus $42 \mathrm{kDa}$ triple gene block protein binds nucleic acids in vitro. J. Gen. Virol. 77:889-897.

Bleykasten-Grosshans, C., Guilley, H., Bouzoubaa, S., Richards, K. E., and Jonard, G. 1997. Independent expression of the first two triple gene block proteins of beet necrotic yellow vein virus complements virus defective in the corresponding gene but expression of the third protein inhibits viral cell-to-cell movement. Mol. Plant-Microbe Interact. 10:240-246.

Brault, V., van den Heuvel, J. F. J. M., Verbeek, M., Ziegler-Graff, V., Reutenauer, A., Herrbach, E., Garaud, J.-C., Guilley, H., Richards, K., and Jonard, G. 1995. Aphid transmission of beet western yellows luteovirus requires the minor capsid readthrough protein P74. EMBO J. 14:650-659.

Davies, C., Hills, G., and Baulcombe, D. C. 1993. Sub-cellular localization of the $25-\mathrm{kDa}$ protein encoded in the triple gene block of potato virus X. Virology 197:166-175.

Deom, C. M., Lapidot, M., and Beachy, R. N. 1992. Plant virus movement proteins. Cell 69:221-224

Donald, R. G. K., Lawrence, D. M., and Jackson, A. O. 1997. The barley stripe mosaic virus 58 -kilodalton $\beta$ b protein is a multifunctional RNA binding protein. J. Virol. 71:1538-1546.

Donald, R. G. K., Shou, H., and Jackson, A. O. 1993. Serological analysis of barley stripe mosaic virus-encoded proteins in infected barley. Virology 195:659-668.

Gilmer, D., Bouzoubaa, S., Hehn, A., Guilley, H., Richards, K., and Jonard, G. 1992a. Efficient cell-to-cell movement of beet necrotic yellow vein virus requires $3^{\prime}$ proximal genes located on RNA 2. Virology 189:40-47.

Gilmer, D., Richards, K., Jonard, G., and Guilley, H. 1992b. Cis-acting sequences near the 5 -termini of beet necrotic yellow vein virus RNAs 3 and 4. Virology 190:55-67.

Ghoshroy, S., Lartey, R., Sheng, J., and Citovsky, V. 1997. Transport of proteins and nucleic acids through plasmodesmata. Annu. Rev. Plant Physiol. Plant Mol. Biol. 48:27-50.

Gorbalenya, A. E., and Koonin, E. V. 1989. Viral proteins containing the purine NTP-binding sequence pattern. Nucleic Acids Res. 17:84138440.

Hefferon, K. L., Doyle, S., and AbouHaidar, M. G. 1997. Immunological detection of the $8 \mathrm{~K}$ protein of potato virus $\mathrm{X}$ (PVX) in cell walls of PVX-infected tobacco and transgenic potato. Arch. Virol. 142:425-433.

Hehn, A., Bouzoubaa, S., Bate, A., Twell, D., Marbach, J., Richards, K., Guilley, H., and Jonard, G. 1995. The small cysteine-rich protein P14 of beet necrotic yellow vein virus regulates accumulation of RNA 2 in cis and coat protein in trans. Virology 210:73-81.

Heinlein, M., Epel, B. L., Padgett, H. S., and Beachy, R. N. 1995. Interaction of tobamovirus movement proteins with the plant cytoskeleton. Science 270:1983-1985.

Herzog, E., Guilley, H., and Fritsch, C. 1995. Translation of the second gene of peanut clump virus RNA 2 occurs by leaky scanning in vitro. Virology 208:215-225.

Herzog, E., Guilley, H., Manohar, S. K., Dollet, M., Richards, K., Fritsch, C., and Jonard, G. 1994. Complete nucleotide sequence of peanut clump virus RNA 1 and relationships with other fungustransmitted rod-shaped viruses. J. Gen. Virol. 75:3147-3155.

Jupin, I., Richards, K., Jonard, G., Guilley, H., and Pleij, C. W. A. 1990. Mapping sequences required for productive replication of beet necrotic yellow vein virus. Virology 178:273-280.

Kalinina, N. O., Fedorkin, O. N., Samuilova, O. V., Maiss, E., Korpela, T., Morozov, S. Y., and Atabekov, J. G. 1996. Expression and biochemical analyses of the recombinant potato virus X $25 \mathrm{~K}$ movement protein. FEBS Lett. 397:75-78

Kasteel, D. T. J., van der Wel, N. N., Jansen, K. A. J., Goldbach, R., and van Lent, J. W. M. 1997a. Tubule-forming capacity of the movement proteins of alfalfa mosaic virus and brome mosaic virus. J. Gen. Virol. 78:2089-2093.

Kasteel, D. T. J., Wellink, J., Goldbach, R. W., and van Lent, J. W. M. 1997b. Isolation and characterization of tubular structures of cowpea mosaic virus. J. Gen. Virol. 78:3167-3170.

Laemmli, U. K. 1970. Cleavage of structural proteins during the assembly of the head of bacteriophage T4. Nature 227:680-685.

Lemaire, O., Merdinoglu, D., Valentin, P., Putz, C., Ziegler-Graff, V., Guilley, H., Jonard, G., and Richards, K. 1988. Effect of beet necrotic yellow vein virus RNA composition on transmission by Polymyxa betae. Virology 162:232-235.

McLean, G. B., Zupan, J., and Zambryzki, P. C. 1995. Tobacco mosaic virus movement protein associates with the cytoskeleton in tobacco cells. Plant Cell 7:2101-2114.

Morozov, S. Y., Fedorkin, O. N., Jüttner, G., Schiemann, J., Baulcombe, D. C., and Atabekov, J. G. 1997. Complementation of a potato virus X mutant mediated by bombardment of plant tissues with cloned viral movement protein genes. J. Gen. Virol. 78:2077-2083.

Morozov, S. Y., Miroschnichenko, N. A., Solovyev, A. G., Fedorkin, O. N., Zelenina, D. A., Lukasheva, L. I., Karasev, A. V., Dolja, V. V., and Atabekov, J. G. 1991. Expression strategy of the potato virus X triple gene block. J. Gen. Virol. 72:2039-2042.

Niesbach-Klösgen, U., Guilley, H., Jonard, G., and Richards, K. 1990. Immunodetection in vivo of beet necrotic yellow vein virus-encoded proteins. Virology 178:52-61.

Oliver, M. J., Deom, C. M., De, G. K., and Beachy, R. N. 1986. In vitro transcription and translation of cloned cDNAs encoding the $30-\mathrm{kDa}$ protein gene of TMV. Virology 155:277-283.

Palukaitis, P., Garcia-Arenal, F., Sulzinski, M. A., and Zaitlin M. 1983. Replication of tobacco mosaic virus VII. Further characterization of single- and double-stranded virus-related RNAs from TMV-infected plants. Virology 131:533-545.

Pringle, C. R. 1997. Virus taxonomy 1997. Arch. Virol. 142:1727-1733.

Quillet, L., Guilley, H., Jonard, G., and Richards, K. 1989. In vitro synthesis of biologically active beet necrotic yellow vein virus RNAs. Virology 172:293-301.

Richards, K. E., and Tamada, T. 1992. Mapping functions on the multipartite genome of beet necrotic yellow vein virus. Annu. Rev. Phytopathol. 30:291-313.

Ritzenthaler, C., Schmit, A.-C., Michler, P., Stussi-Garaud, C., and Pinck, L. 1995. Grapevine fanleaf nepovirus P38 putative movement protein is located on tubules in vivo. Mol. Plant-Microbe Interact. 8: 379-387.

Rouleau, M., Smith, R. J., Bancroft, J. B., and Mackie, G. A. 1994. Purification, properties, and subcellular localization of foxtail mosaic virus 26-kDa protein. Virology 204:254-265.

Sambrook, J., Fritsch, E. F., and Maniatis, T. A. 1989. Molecular Cloning: A Laboratory Manual. 2nd ed. Cold Spring Harbor Laboratory, Cold Spring Harbor, NY.

Schoumacher, F., Giovane, C., Maira, M., Poirson, A., GodefroyColburn, T., and Berna, A. 1994. Mapping of the RNA-binding domain of the alfalfa mosaic virus movement protein. J. Gen. Virol. 75: 3199-3202

Schägger, H., and von Jagow, G. 1987. Tricine-sodium dodecyl sulfatepolyacrylamide gel electrophoresis for the separation of proteins in the range from 1 to $100 \mathrm{kDa}$. Anal. Biochem. 166:368-379.

Solovyev, A. G., Zelenina, D. A., Savenkov, E. I., Grdzelishvili, V. Z. Morozov, S. Y., Lesemann, D. E., Maiss, E., Casper, R., and Atabekov, J. G. 1996. Movement of a barley stripe mosaic virus chimera with a tobacco mosaic virus movement protein. Virology 217:435-441.

Van Lent, J., Wellink, J., and Goldbach, R. 1990. Evidence for the involvement of the $58 \mathrm{~K}$ and $48 \mathrm{~K}$ proteins in the intracellular movement of cowpea mosaic virus. J. Gen. Virol. 71:219-223.

Veidt, I., Bouzoubaa, S. E., Leiser, R. M., Ziegler-Graff, V., Guilley, H., Richards, K., and Jonard, G. 1992. Synthesis of full-length transcripts of beet western yellows virus RNA: Messenger properties and biological activity in protoplasts. Virology 186:192-200.

Zheng, H., Wang, G., and Zhang, L. 1997. Alfalfa mosaic virus movement protein induces tubules in plant protoplasts. Mol. Plant-Microbe Interact. 10:1010-1014.

Zhou, H., and Jackson, A. O. 1996. Expression of the barley stripe mosaic virus RNA $\beta$. Virology 216:367-379. 